\title{
МОНИТОРИНГ НАРУШЕННЫХ ЗЕМЕЛЬ ТЕРРИТОРИИ НОВИКОВСКОГО БУРОУГОЛЬНОГО МЕСТОРОЖДЕНИЯ (ЮГО-ВОСТОК ОСТРОВА САХАЛИН)
}

\section{Алексей Александрович Верхотуров}

Институт морской геологии и геофизики Дальневосточного отделения Российской академии наук, 693022, Россия, г. Южно-Сахалинск, ул. Науки, 1Б, кандидат технических наук, старший научный сотрудник Центра коллективного пользования, тел. (914)760-68-87, e-mail: ussr-91@mail.ru

\section{Анастасия Андреевна Попова}

Сахалинский государственный университет, 693023, Россия, г. Южно-Сахалинск, ул. Пограничная, 2, обучающийся, тел. (914)088-75-92, e-mail: nastya09896@mail.ru

Нерекультивированные карьеры способствуют возникновению и развитию множества негативных процессов и явлений на прилегающей к месторождению территории, представляют собой малопригодные для хозяйственного освоения технгенно-нарушенные ландшафты. Исследование вопросов естественного восстановления нарушенных земель, имеет очевидную теоретическую и практическую значимость. В работе представлены результаты пространственно-временного анализа состояния растительного покрова на территории Новиковского буроугольного месторождения. На основе использования космических снимков среднего разрешения систем Landsat и Sentinel за период с 1980 по 2020 гг. в геоинформационной среде были рассчитаны значения NDVI, определен современный состав растительного покрова, что позволило проследить динамику и характер сукцессии на пораженной территории.

Ключевые слова: дистанционное зондирование Земли, мониторинг земель, нарушенные земли, вегетационный индекс, угольный карьер

\section{MONITORING OF DISTURBED LAND ON THE TERRITORY OF THE NOVIKOV BROWN COAL DEPOSIT (SOUTH-EAST OF SAKHALIN ISLAND)}

\section{Alexey A. Verkhoturov}

Institute of Marine Geology and Geophysics of the Far Eastern branch of the Russian Academy of Sciences, 1B, Nauki St., Yuzhno-Sakhalinsk, 693022, Russia, Ph. D., Senior Researcher of the Center for Collective Use, phone: (914)760-68-87, e-mail: ussr-91@mail.ru

\section{Anastasiya A. Popova}

Sakhalin State University, 2, Pogranichnaya St., Yuzhno-Sahalinsk, 693023, Russia, Student, phone: (914)088-75-92, e-mail: nastya09896@mail.ru

Non-recultivated pit contribute to emergence and development of many negative processes and effects in adjacent territory, and they are poorly suited for economic development of technogenic-disturbed landscapes. The research of natural restoration of disturbed lands is of obvious theoretical and practical significance. The work presents the results of spatial and temporal analysis of the state of vegetation cover on the territory of the Novikov brown coal Deposit. Based on mediumresolution satellite images of the Landsat and Sentinel systems for the period from 1980 to 2020, NDVI values were calculated in GIS, and the current composition of vegetation cover was determined, which made it possible to trace the dynamics and nature of successions in the affected area.

Keywords: remote sensing of the Earth, monitoring land, disturbed lands, vegetation index, coal pit 
В структуре промышленного производства Сахалинской области лидирующие позиции занимают угольная промышленность и нефтегазовый комплекс.

В постсоветское время добыча угля в шахтах сменилась менее затратным открытым способом. В свою очередь изменение технологии добычи горючих полезных ископаемых привело к интенсификации негативного воздействия на окружающую среду и как следствие к образованию на значительных территориях техногенных ландшафтов.

В отечественной и зарубежной научной литературе активно обсуждаются вопросы связанные негативным воздействием горной промышленности на окружающую среду, рекультивации и темпов сукцессии на территориях отработанных карьеров [1-8].

К сожалению, большинство отработанных карьеров не рекультивируются. Заброшенные карьеры, способствуют возникновению и развитию ряда негативных процессов на прилегающей территории. Изменяются гидрологический и гидрогеологический режимы прилегающей территории. Так они являются дополнительным источником увлажнения и подтопления, и как следствие заболачиваются.

На крутых откосах возникают оползни и осыпи. В период обильных осадков и снеготаяния повышается концентрация взвешенных частиц грунта в нерестовых водотоках.

Исследование вопросов естественного восстановления нарушенных земель имеет очевидную теоретическую и практическую значимость.

Для понимания механизма и темпов восстановления почвенно- растительного покрова в конкретных природно-климатических условиях, планирования мероприятий по рекультивации и борьбе с негативными инженерногеологическими процессами необходимо проводить мониторинг земель, занятых бывшими карьерами [9-10].

В работе приведены результаты исследования пространственно-временных изменений растительного покрова на территории Новиковского буроугольного месторождения на основе нормализованного относительного вегетационного индекса (NDVI) (рис. 1).

В ходе исследования был выполнен сбор и анализ доступных космоснимков систем Landsat 1-8 и Sentinel-2 за интервал времени с 1980 по 2020 г. [11]. При выборе снимков основными критериями являлись: время съемки в вегетационный период (июль-сентябрь) и отсутствие облачности над областью интереса. Всего было отобрано 5 сцен.

В качестве оценочного средства пространственно-временных изменений растительного покрова применялся нормализованный относительный вегетационный индекс (NDVI), а также синтезированные снимки. 


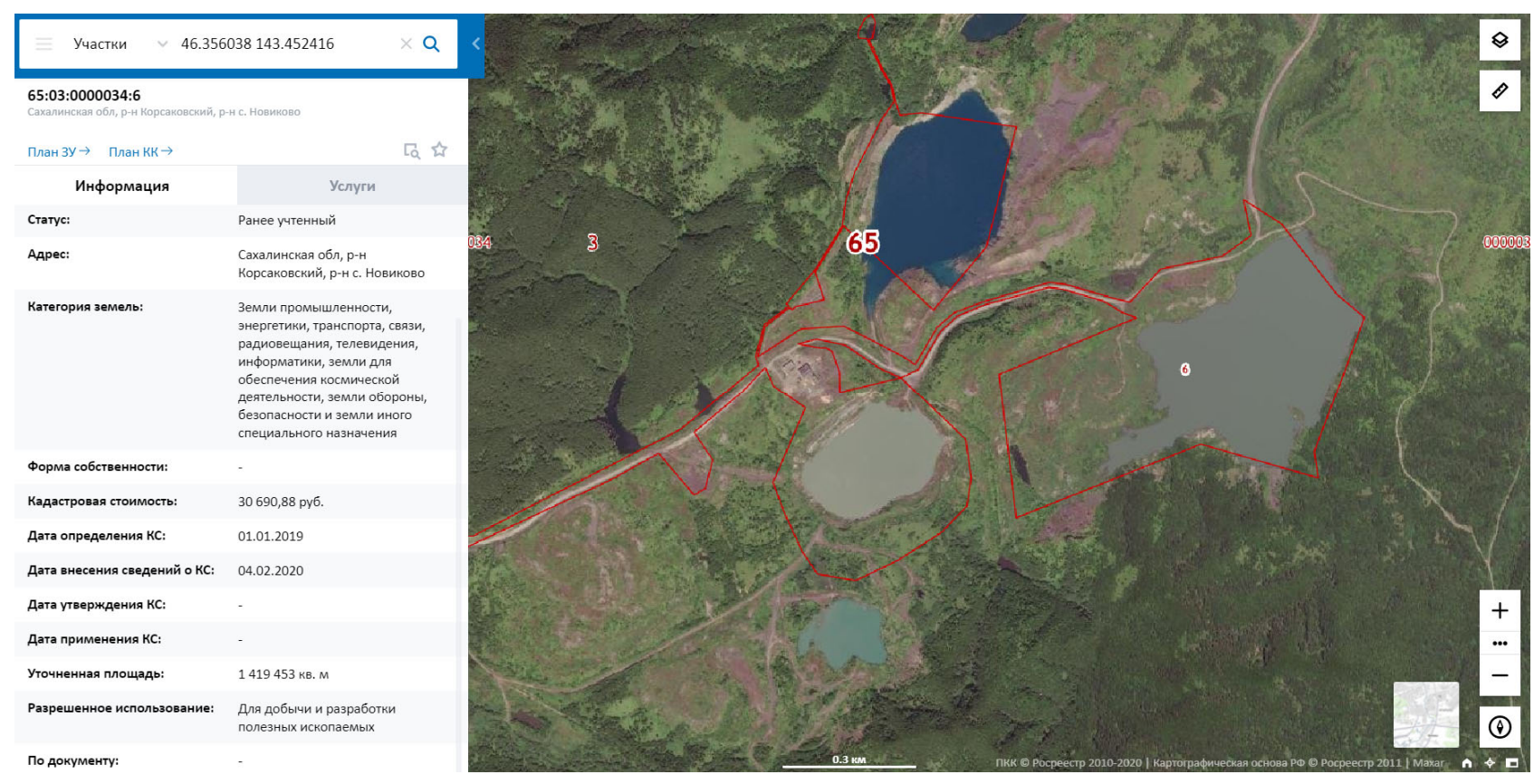

Рис. 1. Территория Новиковского буроугольного месторождения на Публичной кадастровой карте

После проведения атмосферной коррекции и расчета NDVI в среде ГИС получен ряд карт-схем, отражающих количество фотосинтетически активной биомассы (рис. 2). Полученные NDVI-сцены были расклассифицированы на пять категорий с подсчетом площадей, сумма которых составила 3442 га (таблица).

Суммарные площади полигонов с различными значениями NDVI по годам, га

\begin{tabular}{|l|l|l|l|l|l|}
\hline $\begin{array}{l}\text { 3начение Дата съемки } \\
\text { NDVI }\end{array}$ & 18.09 .1980 & 17.08 .1990 & 21.09 .2000 & 9.09 .2010 & 18.07 .2020 \\
\hline$<0$ & 4,66 & 5,20 & 59,99 & 71,70 & 0,00 \\
\hline $0-0,2$ & 106,65 & 34,02 & 50,42 & 30,38 & 28,35 \\
\hline $0,2-0,3$ & 58,58 & 164,19 & 69,67 & 49,35 & 35,68 \\
\hline $0,3-0,5$ & 1021,09 & 356,83 & 1237,43 & 2945,51 & 58,86 \\
\hline$>0,7$ & 2251,02 & 2881,76 & 2024,49 & 345,06 & 3319,11 \\
\hline
\end{tabular}

Площадь нарушенных земель увеличивалась до 1990 г. в результате освоения новых участков месторождения. В дальнейшем же можно наблюдать, что отработка месторождения происходит в устоявшихся границах. В то же время на ранее отработанных блоках происходит восстановление растительного покрова и подтопление горных выемок. После закрытия карьера в 2003 г. темпы сукцессии увеличились и к 2020 г. высокие значения NDVI наблюдаются на всей территории месторождения, за исключением техногенных озер, крутых откосов и дорог. 

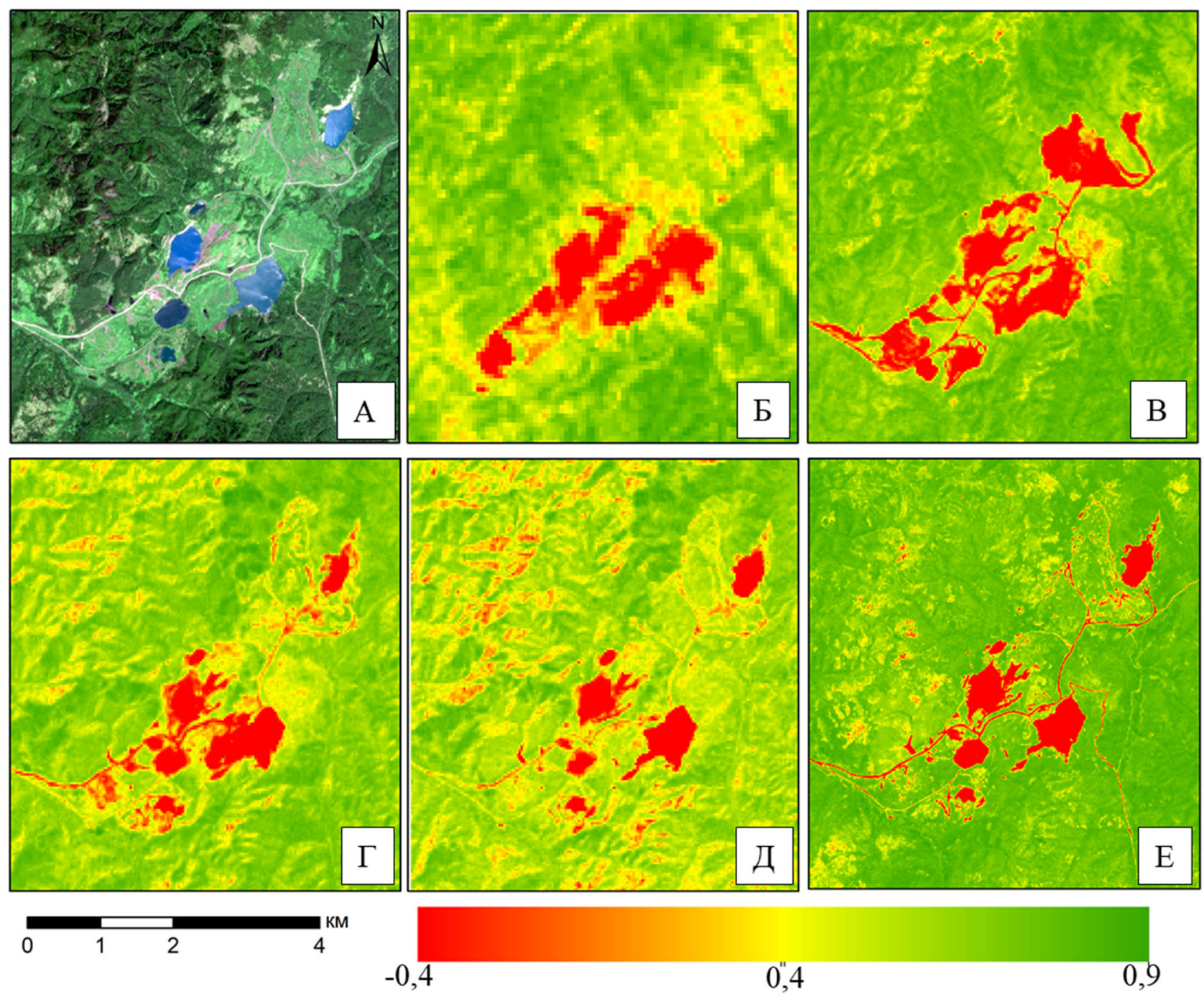

Рис. 2. Результаты расчета NDVI на территории Новиковского месторождения:

А - состояние на 2020 г. (видимая зона спектра); Б - 1980 г.; В - 1990 г.;

$$
\text { Г-2000 г.; Д - } 2010 \text { г.; Е - } 2020 \text { г. }
$$

На основе синтезированного космического снимка Sentinel-2 в комбинации каналов 8-4-3 произведена неконтролируемая классификация изокластеров и составлена карт-схема современного состояния растительного покрова территории Новиковского буроугольного карьера (рис. 3).

Преобладающим растительным сообществом исследуемой территории являются березовые леса ( $54 \%$ от общей площади), в том числе березовые редколесья на техногенно-нарушенных землях. На долю хвойных пихтово-еловых лесов приходится $32 \%$, вейниковые луга и заросли бамбук - $11 \%$. Техногенные озера на месте бывших горных выработок занимают 3 \% территории.

Результаты исследования подтверждают целесообразность применения современных средств дистанционного зондирования и геоинформационных технологий для изучения динамики и характера естественного восстановления 

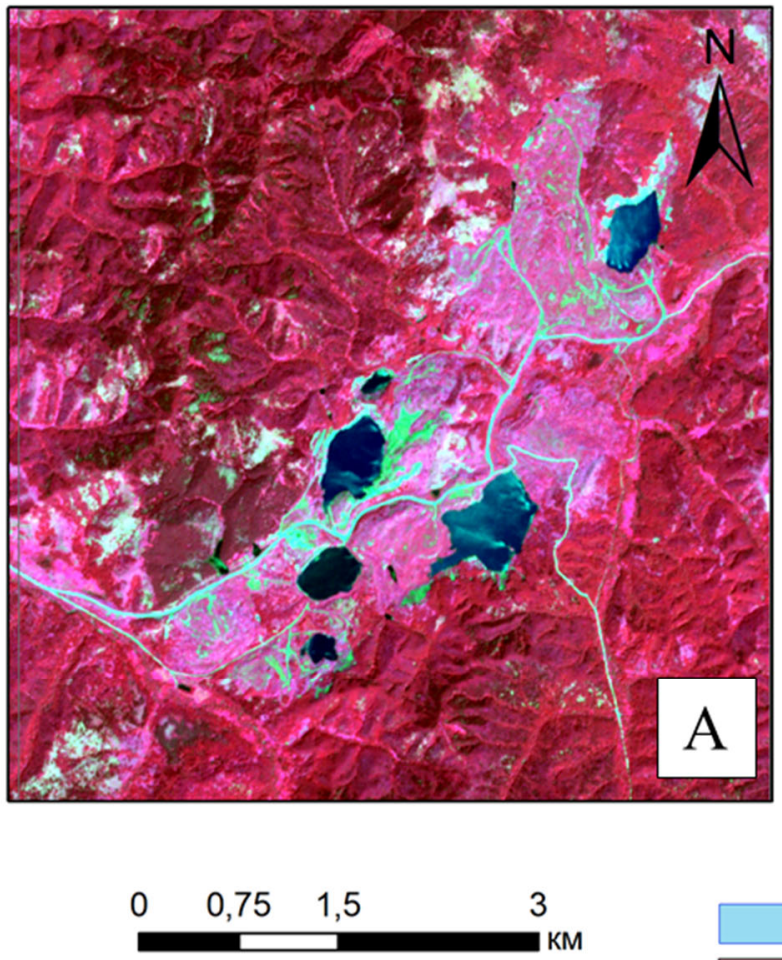

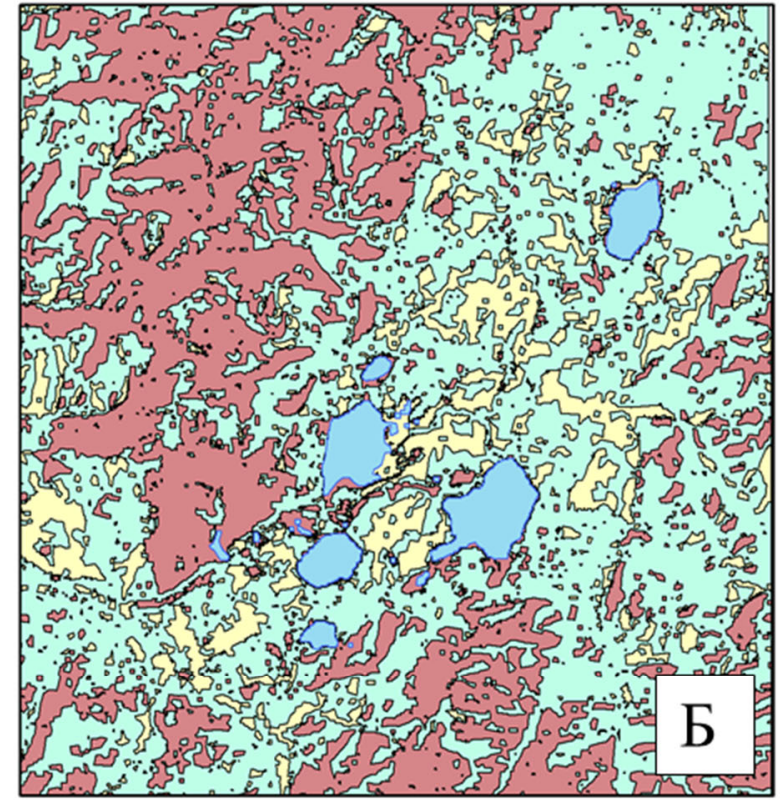

ЛЕГЕНДА

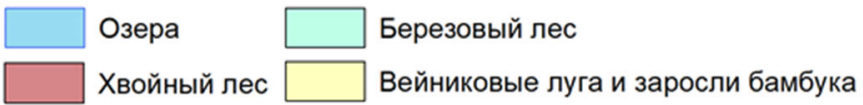

Рис. 3. Современный состав растительного покрова: A - снимок Sentinel-2 в комбинации каналов 8-4-3; Б - результат классификации

\section{БИБЛИОГРАФИЧЕСКИЙ СПИСОК}

1. Романов, А. В., Чибисов, А. С., Мелкий, В. А., Верхотуров, А. А. Минеральные ресурсы Сахалинской области и перспективы их использования // Горный журнал. - 2017. № 7. - С. 17-24.

2. Верхотуров, А. А., Мелкий, В. А. Угольные ресурсы Сахалинской области // Горный журнал. - 2017. - № 7. - С. 24-28.

3. Яницкий, Е. Б. Геоэкологическая оценка и мониторинг антропогенного воздействия горной промышленности Курской магнитной аномалии с использованием ГИС: на примере Старооскольско-Губкинского района: дис. ... к-та. геогр. наук: 25.00.36 / Яницкий Евгений Брониславович. - Белгород, 2009. - 145 с.

4. Пашкевич, М. А., Левчук И. Р. Оценка и снижение негативного воздействия намывных массивов угледобывающих предприятий на природную среду // Записки Горного института. - 2013. - Т. 203. - С. 86-89.

5. Папичев, В. И., Прошляков, А. Н. Физические процессы взаимодействия природных и технических систем при открытой разработке полезных ископаемых. - Экологические системы и приборы. - 2018. - № 6. - С. 49-54.

6. Huang, Y., Tian, F., Wang, Y. et al. Effect of coal mining on vegetation disturbance and associated carbon loss. Environ Earth Sci 73, 2329-2342 (2015). https://doi.org/10.1007/s12665014-3584-z. 
7. Wang C. (2013) Study on Plants Community Succession in Land for Coal Gangue Dump in Fushun Mining Area. In: Du W. (eds) Informatics and Management Science I. Lecture Notes in Electrical Engineering, vol 204. Springer, London. https://doi.org/10.1007/978-1-4471-4802-9_31.

8. Li, X., Lei, S., Cheng, W. et al. Spatio-temporal dynamics of vegetation in Jungar Banner of China during 2000-2017. J. Arid Land 11, 837-854 (2019). https://doi.org/10.1007/s40333-0190067-9.

9. Мелкий, В. А., Верхотуров, А. А., Попова, Я. П., Бурыкин, А. Н. Мониторинг состояния земель и оценка динамики антропогенного воздействия на территорию Сахалина // Известия Томского политехнического университета. Инжиниринг георесурсов - 2018. - № 6. C. $48-57$.

10. Мелкий, В. А. Технология комплексного мониторинга состояния земель и динамики природных процессов в Сахалинской области / В. А. Мелкий, А. А. Верхотуров // ИнтерКарто/ИнтерГИС 23. Геоинформационное обеспечение устойчивого развития территорий в условиях глобальных изменений климата: материалы Междунар. конф. - М. : Издательство Московского университета, 2017. - Т. 3. - С. 178-194.

11. Сайт United States Geological Survey (USGS) [Электронный ресурс]. - Режим доступа: https://doi.org/earthexplorer.usgs.gov/.

(C) A. A. Верхотуров, А. А. Попова, 2021 